\title{
ORIGINAL ARTICLE \\ Centralized spinal cord injury care in Finland: unveiling the hidden incidence of traumatic injuries
}

\author{
EA Koskinen ${ }^{1}$, M Alen²,3, EM Väärälä ${ }^{1}$, J Rellman $^{1}$, M Kallinen ${ }^{2}$ and A Vainionpää ${ }^{2}$
}

Study design: Population-based prospective study.

Objectives: To determine the incidence and evaluate the characteristics of newly injured patients with traumatic spinal cord injury (TSCl) admitted to two of the three national spinal cord injury (SCI) centers during the first year after the centralization of SCl care in Finland.

Setting: Oulu and Tampere University Hospital SCI centers, Finland.

Methods: The designated rehabilitation teams evaluated all of the patients with a new SCl and persisting neurological symptoms. The data were recorded according to the International Spinal Cord Injury Core Data Set.

Results In a 1-year period, 77 new patients with TSCI were admitted to the study centers serving a population of 3065946 . In the whole catchment area, the mean annual incidence of TSCI was 25.1 per million, and in the hospital districts of the SCI centers, the incidence was even higher, at 38.1 per million. The mean age of the patients was 58.7 years. Falls were the leading cause of injury $(64.9 \%)$, and the injury resulted in tetraplegia in $70.1 \%$ of the cases. Alcohol use was a contributing factor in $39 \%$ of the cases in the entire sample and in 58.6\% of cases among patients aged younger than 60 years.

Conclusion The incidence rates of TSCl were markedly higher than expected, demonstrating the previously hidden morbidity. The epidemiological features of TSCl appeared to follow the trends in developed countries, highlighting the increasing incidence of cervical lesions due to falling among the elderly. The results need to be confirmed in an extended follow-up.

Spinal Cord (2014) 52, 779-784; doi:10.1038/sc.2014.131; published online 12 August 2014

\section{INTRODUCTION}

Finland is a quite large and relatively sparsely populated Nordic country (303891 km², 5.4 million inhabitants), and its health care system is primarily public and financed by taxes. Traffic and occupational injuries are covered by the private insurance system, but the acute phase of severe injuries such as spinal cord injuries (SCIs) is always treated in public hospitals. Previously, the acute care and possible surgical management of new patients with SCI in Finland was divided into 21 different hospital districts responsible for organizing the specialized medical care. After acute care, some SCI patients, primarily those of the working-age, were referred to the private Käpylä Rehabilitation Centre. The rehabilitation of the remaining patients was performed primarily in the rehabilitation units of local hospitals or health centers with variable resources and protocols. In addition, depending on the area of Finland, there are wide variations in organizing the life-long follow-up, varying from follow-up at multidisciplinary SCI outpatient clinics to non-existent follow-up.

Internationally specialized SCI centers have been established to improve the care and recovery of the patients with SCI. Integrated multidisciplinary specialized SCI centers are supported by the tentative research data and expert panel recommendations to decrease the length of stay, overall mortality, and number and severity of complications. ${ }^{1,2}$ To alter the heterogeneous and fragmented situation of SCI care in Finland, the patient organization has stressed the need to follow international recommendations to centralize SCI care in integrated multidisciplinary SCI units with adequate resources. After years of effort, the new Health Care Act also contained a decree to centralize highly specialized medical care, including SCI care. ${ }^{3}$ The decree took effect on 1 May 2011. The acute care, subacute rehabilitation and lifelong follow-up of patients with SCI were centralized into three University Hospitals (UHs): Helsinki, Oulu and Tampere. A national SCI care advisory board, containing representatives from all five university hospitals and a patient organization, was established to guide the practical execution of the decree.

After the decree of centralization was issued, the epidemiology of SCI was of great importance in organizing the service and allocating the facilities and other resources in the SCI centers. However, there is no SCI registry in Finland, and only one report about the incidence of traumatic SCI (TSCI) was published in the past two decades. Ahoniemi et al. ${ }^{4}$ reported an annual incidence rate of 13.8 per million in the population aged 16 years or older based on the data from the records of Käpylä Rehabilitation Centre over the period between 1976 and 2005. Studies from other Nordic countries have reported an annual incidence of TSCI reaching 9.2 per million inhabitants per year in Denmark, ${ }^{5} 19.5$ in the greater Stockholm region in Sweden, ${ }^{6} 26.3$ in western Norway ${ }^{7}$ and 33.5 in Iceland. ${ }^{8}$

The aim of this study was to obtain population-based epidemiological and outcome data for medical care and follow-up planning as well as for preventive initiatives. Furthermore, our intention was to

${ }^{1}$ Department of Neuroscience and Rehabilitation, Tampere University Hospital, Tampere, Finland; ${ }^{2}$ Department of Medical Rehabilitation, Oulu University Hospital, Oulu, Finland and ${ }^{3}$ Institute of Health Sciences, University of Oulu, Oulu, Finland

Correspondence: Dr EA Koskinen, Department of Neurosciences and Rehabilitation, Tampere University Hospital, PL 2000,33521 Tampere, Finland.

E-mail: eerika.koskinen@uta.fi

Received 9 April 2014; revised 28 May 2014; accepted 8 July 2014; published online 12 August 2014 
monitor the implementation of centralized care throughout the catchment areas.

\section{MATERIALS AND METHODS}

\section{Design}

The study was a prospective 1-year population-based epidemiological study in two of the three newly appointed SCI centers in Finland, which covered 3065946 (56.5\% of the population) individuals in all age groups during the study period. All patients with SCI caused by an external force were included in this study. Patients with non-traumatic etiologies were excluded.
Both the Oulu and Tampere UHs have previously provided general neurorehabilitation and used outpatient follow-up clinics for SCI patients for many years. These resources have now been increased, although Käpylä Rehabilitation Centre is still being used for some selected patients after the acute period and following evaluation in SCI centers. These rehabilitation periods were included in the study. The study areas and population are described in Figure 1.

Evaluation of new SCI patients admitted to these centers according to the International Spinal Cord Society (ISCoS) Core Data Set principles started in Tampere UH on 1 January 2012 and in Oulu UH on 1 May 2012. The results of the first year after starting the protocol are presented; Tampere UH: 1

Oulu University Hospital SCI centre area:

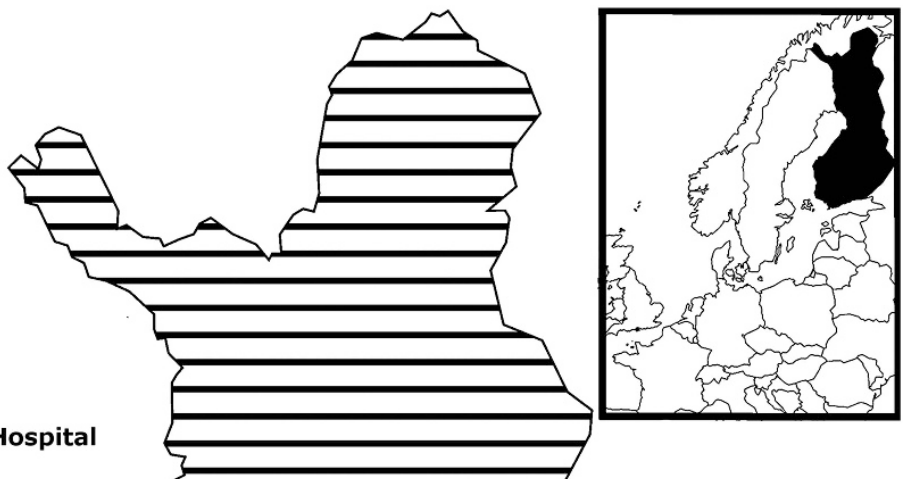

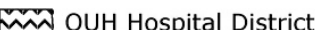
쓰 Population: 400959

Other hospital districts Population: 338516

Tampere University Hospital SCI centre area:

333. TAUH Hospital District 333 Population: 518157 Population: 1808314

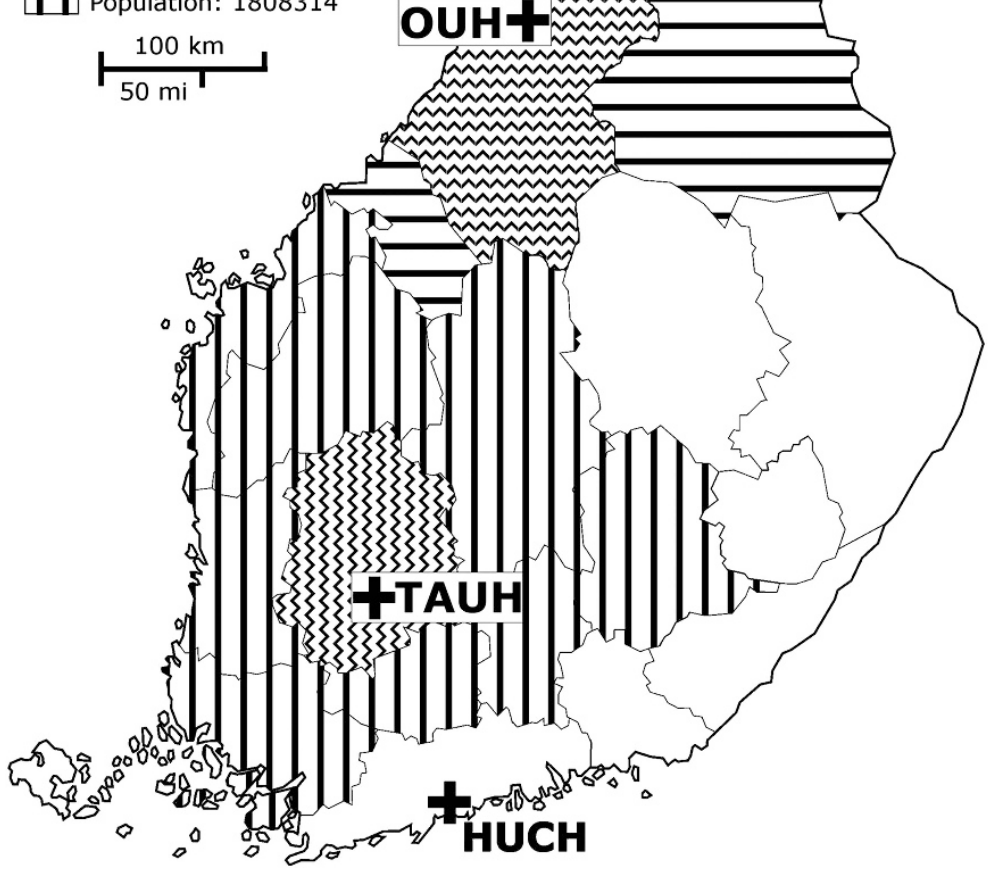

Figure 1 Finland is divided into 20 hospital districts in the mainland and one on the autonomous Åland Islands. The districts are responsible for specialized health care (tertiary care) and are municipality financed and governed. Five of these hospital districts are university hospital districts supporting the central hospital districts in their region and also providing government-defined highly specialized medical care. Spinal cord injury care is centralized in the university hospitals in Helsinki (HUCH), Oulu (OUH) and Tampere (TAUH). 
January 2012 to 31 December 2013 and Oulu UH: 1 May 2012 to 30 April 2013. Currently, data from the third SCI center in Helsinki University Central Hospital are missing because the unit was opened only in the second half of the year 2013 in the form of an outpatient clinic.

Following institutional and governmental regulations, study approval was obtained from both the UH administrations. Ethics committee approval was not required, as all data were collected during the standard practice.

\section{Subjects and procedure}

In both SCI centers, a multidisciplinary SCI rehabilitation team is routinely informed of all patients admitted to the hospital with a new SCI and persisting neurological symptoms, regardless of the cause, level or completeness of injury. However, this practice does not apply to patients with progressive neurological diseases, such as multiple sclerosis or amyotrophic lateral sclerosis. The consultant specialist physician of the SCI unit with the support of rehabilitation team performs the clinical evaluation and assessment to plan and initiate the rehabilitation and follow-up program.

The Oulu and Tampere UHs are the only trauma, intensive care, neurosurgery and spine surgery units in their own hospital districts, serving a population of 400959 in Oulu and 518157 in Tampere (Figure 1). Thus, all newly injured SCI patients in these hospital districts should come to the attention of these SCI centers. When considering the entire catchment area of SCI centers, there are several trauma and intensive care units, and referral to the SCI centers is less certain.

\section{Collection of clinical data}

The International Standards for Neurological Classification of Spinal Cord Injury ${ }^{9}$ were used to evaluate and classify the neurological consequence of SCI, and epidemiological characteristics were collected and classified using the International SCI Core Data Set. ${ }^{10}$ In addition, the ability to move at the time of discharge was classified into six categories, and the influence of alcohol at the time of the injury was retrospectively recorded from the medical records.

\section{Statistical analyses}

The incremental number of TSCI cases in all age groups and their clinical features over a consecutive 12-month follow-up period are reported in this article. Data were analyzed as a whole, but further comparisons were also drawn with regard to age and hospital district. Continuous variables are presented as the mean, (s.d.) and median (range). The Mann-Whitney test was used to calculate the differences between patient groups. For categorical variables, the number and percentage are shown, and the differences between groups were examined by Fischer's exact test. Statistical significance was set at $P<0.05$. Incidence rates were calculated using the population on 31 December 2012 according to the Official Statistics of Finland. ${ }^{11}$ SPSS version 20.0 (IBM, Armonk, NY, USA) was used to perform all of the statistical analyses.

\section{RESULTS}

\section{Incidence}

The incidence of TSCI is shown in Table 1. In the 1-year period, 77 new patients with TSCI were admitted to the Oulu and Tampere UH SCI centers. Of those patients, 35 were residents of the Tampere and Oulu UH's own hospital districts and 42 were referred from other hospital districts in the catchment area of the SCI centers. The annual incidence of TSCI patients in the entire catchment area was 25.1 per million, and that in the age group over 16 years was 29.8 per million in the subgroup population of 2516942 people. In the hospital districts of the Oulu and Tampere UHs with integrated trauma and SCI centers, the incidence was 38.1 per million inhabitants, and in the age group over 16 years, the incidence was 46.0 per million in the subgroup population of 739338 people. There were only two cases of TSCI in the age group under 16 years presenting incidence of 3.6 per million in the population of 549004 .
Table 1 Annual incidence of TSCI patients referred to two of the three $\mathrm{SCl}$ centers in Finland and the severity of the injuries

\begin{tabular}{lccc}
\hline & All & $\begin{array}{c}\text { Hospital districts } \\
\text { of Oulu and } \\
\text { Tampere UH }\end{array}$ & $\begin{array}{c}\text { Other hospital } \\
\text { districts in the } \\
\text { SCl centers } \\
\text { catchment area }\end{array}$ \\
& & & 2146830 \\
\hline Population & 3065946 & 919116 & 42 \\
Number of cases & 77 & 35 & 19.6 \\
Incidence/million & 25.1 & 38.1 & \\
Neurological category (\%) & & & $2(4.8)$ \\
Ventilator dependent & $4(5.2)$ & $2(5.7)$ & $2(4.8)$ \\
C1-C4 AIS A, B, C & $13(16.9)$ & $3(8.6)$ & $7(16.7)$ \\
C5-C8 AIS A, B, C & $4(5.2)$ & $2(5.7)$ & $20(47.6)$ \\
T1-S5 AIS A, B, C & $12(15.6)$ & $5(14.3)$ & - \\
All AIS D & $39(50.6)$ & $19(54.3)$ & $2(2.4)$ \\
AIS E & $2(2.6)$ & $2(5.7)$ & \\
Unknown & $3(3.9)$ & $2(5.7)$ & \\
\hline
\end{tabular}

Abbreviations: AIS, American Spinal Injury Association Impairment Scale; AIS A, motor-sensory complete; AIS B, motor complete-sensory incomplete; AIS C-D, motor-sensory incomplete; AIS $\mathrm{E}$, normal examination; SCI, spinal cord injury; TSCl, traumatic spinal cord injury; UH, University Hospital.

\section{Characteristics of TSCIs}

The epidemiological characteristics of the TSCI patients, the treatment periods, the outcomes and the comparisons between groups are shown in Table 2. Of all TSCI patients, 52 were male and 25 were female, giving a male-to-female ratio 2.1/1. The mean age at injury was 58.7 years, and falls were the leading cause of injury (64.9\%), followed by transportation accidents $(18.2 \%)$. The injury resulted in tetraplegia in $70.1 \%$ of cases and paraplegia in $29.9 \%$. The place of discharge was most often a private residence, and $44.6 \%$ of the patients were able to walk without or with equipment at the time of discharge. The distributions of the place of discharge and the ability to move at the time of discharge differed significantly when comparing patients from the Oulu and Tampere UH's own hospital districts with patients referred from other hospital districts. The patients from Oulu and Tampere UH's own hospital districts were mainly discharged directly to the private residence (71.4\%), whereas other hospital was the most prevalent place of discharge for the group of patients from other hospital districts $(45.2 \%)$. In the same study groups, the proportions of patients able to walk without assistive devices at the time of discharge were $45.5 \%$ and $17.1 \%$, respectively.

\section{Effect of age on injury characteristics}

Of the patients with TSCI, 29 individuals were younger than 60 years and 48 were $\geqslant 60$ years of age giving the incidence of 12.9 per million and 58.3 per million in the populations of 2242163 and 823783 , respectively. (Table 2) The male-to-female ratio was higher among the younger age group $(2.6 / 1)$ than in the older $(1.8 / 1)$. In relation to the etiology of injury, the neurological level of injury, the total days hospitalized and the place of discharge, there was a statistically significant difference between patient groups by age. In the patient group $\geqslant 60$ years of age, $85.4 \%$ were injured by falling, whereas among younger patients, transportation comprised $37.9 \%$ and falls $31.0 \%$ of the external causes of injury. In the older age group, $81.3 \%$ were tetraplegic, whereas in the younger age group, the distribution between tetra- and paraplegia was even. In the age group $\geqslant 60$ years of age among the patients with tetraplegia, $72.2 \%$ had a high cervical neurological lesion (C1-C4). In the group of patients $<60$ years of 
Table 2 Epidemiological characteristics, treatment periods and outcomes of new patients with $\mathrm{TSCl}$ in two of the three $\mathrm{SCl}$ centers in Finland over a 1-year follow-up period

\begin{tabular}{|c|c|c|c|c|c|c|c|}
\hline & All & $\begin{array}{l}\text { Hospital districts } \\
\text { of Oulu and } \\
\text { Tampere UH }\end{array}$ & $\begin{array}{l}\text { Other hospital } \\
\text { districts in the } \\
\text { SCl centers } \\
\text { catchment area }\end{array}$ & $\mathrm{P}$-value & Under 60 & Over 60 & P-value \\
\hline $\begin{array}{l}\text { Population } \\
\text { Number of cases } \\
\text { Gender (male/female) } \\
\text { Age at injury, Mean } \pm \text { s.d. } \\
\text { Median (range) }\end{array}$ & $\begin{array}{c}3065946 \\
77 \\
2.1 / 1 \\
58.7 \pm 19.8 \\
63.4(2.8-89.5)\end{array}$ & $\begin{array}{c}919116 \\
35 \\
1.9 / 1 \\
55.7 \pm 20.1 \\
62.3(6.3-78.2)\end{array}$ & $\begin{array}{c}2146830 \\
42 \\
2.2 / 1 \\
61.2 \pm 19.4 \\
64.5(2.8-89.5)\end{array}$ & $\begin{array}{l}0.810 \\
0.192\end{array}$ & $\begin{array}{c}2242163 \\
29 \\
2.6 / 1 \\
37.8 \pm 15.4 \\
41.3(2.8-59.6)\end{array}$ & $\begin{array}{c}823783 \\
48 \\
1.8 / 1 \\
71.3 \pm 7.8 \\
70.4(60.2-89.5)\end{array}$ & $\begin{array}{l}0.617 \\
\underline{0.000} \\
\end{array}$ \\
\hline $\begin{array}{l}\text { Injury etiology (\%) } \\
\text { Sports } \\
\text { Assault } \\
\text { Transport } \\
\text { Fall } \\
\text { Other traumatic cause }\end{array}$ & $\begin{aligned} 6 & (7.8) \\
1 & (1.3) \\
14 & (18.2) \\
50 & (64.9) \\
6 & (7.8)\end{aligned}$ & $\begin{aligned} 1 & (2.9) \\
1 & (2.9) \\
6 & (17.1) \\
24 & (68.6) \\
& 3(8.6)\end{aligned}$ & $\begin{aligned} & (11.9) \\
& - \\
8 & (19.0) \\
26 & (61.9) \\
3 & (7.1)\end{aligned}$ & 0.526 & $\begin{aligned} 6 & (20.7) \\
1 & (3.4) \\
11 & (37.9) \\
9 & (31.0) \\
2 & (6.9)\end{aligned}$ & $\begin{aligned} & - \\
3 & (6.3) \\
41 & (85.4) \\
4 & (8.3)\end{aligned}$ & 0.000 \\
\hline $\begin{array}{l}\text { Vertebral injury (\%) } \\
\text { Associated injury (\%) } \\
\text { Spinal surgery (\%) }\end{array}$ & $\begin{array}{r}64(83.1) \\
9(11.7) \\
72(93.5)\end{array}$ & $\begin{array}{r}27(77.1) \\
4(11.4) \\
31(88.6)\end{array}$ & $\begin{array}{r}37(88.1) \\
5(11.9) \\
41(97.6)\end{array}$ & $\begin{array}{l}0.234 \\
1.000 \\
0.171\end{array}$ & $\begin{array}{r}23(79.3) \\
5(17.2) \\
27(93.1)\end{array}$ & $\begin{aligned} 41 & (85.4) \\
4 & (8.3) \\
45 & (93.8)\end{aligned}$ & $\begin{array}{l}0.539 \\
0.285 \\
1.000\end{array}$ \\
\hline $\begin{array}{l}\text { Neurological level of injury (\%) } \\
\text { Tetraplegia } \\
\text { Paraplegia }\end{array}$ & $\begin{array}{l}54(70.1) \\
23(29.9)\end{array}$ & $\begin{array}{l}23(65.7) \\
12(34.3)\end{array}$ & $\begin{array}{ll}31 & (73.8) \\
11 & (26.2)\end{array}$ & 0.464 & $\begin{array}{l}15(51.7) \\
14(48.3)\end{array}$ & $\begin{array}{r}39(81.3) \\
9(18.8)\end{array}$ & 0.010 \\
\hline $\begin{array}{l}\text { C1-C4 } \\
\text { C5-C8 } \\
\text { T1-T12 } \\
\text { L1-S5 } \\
\text { Unknown }\end{array}$ & $\begin{array}{l}34(44.2) \\
15(19.5) \\
18(23.4) \\
5(6.5) \\
5(6.5)\end{array}$ & $\begin{aligned} 12 & (34.3) \\
8 & (22.9) \\
9 & (25.7) \\
3 & (8.6) \\
3 & (8.6)\end{aligned}$ & $\begin{aligned} 22 & (52.4) \\
7 & (16.7) \\
9 & (21.4) \\
2 & (4.8) \\
2 & (4.8)\end{aligned}$ & 0.509 & $\begin{aligned} 8 & (27.6) \\
6 & (20.7) \\
10 & (34.5) \\
4 & (13.8) \\
1 & (3.4)\end{aligned}$ & $\begin{array}{c}26(54.2) \\
9(18.8) \\
8(16.7) \\
1(2.1) \\
4(8.3)\end{array}$ & 0.026 \\
\hline $\begin{array}{l}\text { ASIA Impairment Scale (\%) } \\
\text { AIS A } \\
\text { AIS B } \\
\text { AIS C } \\
\text { AIS D } \\
\text { AIS E } \\
\text { Unknown }\end{array}$ & $\begin{aligned} 14 & (18.2) \\
12 & (15.6) \\
7 & (9.1) \\
39 & (50.6) \\
2 & (2.6) \\
3 & (3.9)\end{aligned}$ & $\begin{aligned} 3 & (8.6) \\
5 & (14.3) \\
4 & (11.4) \\
19 & (54.3) \\
2 & (5.7) \\
2 & (5.8)\end{aligned}$ & $\begin{aligned} 11 & (26.2) \\
7 & (16.7) \\
3 & (7.1) \\
20 & (47.6) \\
- & (2.4)\end{aligned}$ & 0.178 & $\begin{aligned} 6 & (20.7) \\
5 & (17.2) \\
2 & (6.9) \\
16 & (55.2) \\
& - \\
& -\end{aligned}$ & $\begin{aligned} 8 & (16.7) \\
7 & (14.6) \\
5 & (10.4) \\
23 & (47.9) \\
2 & (4.2) \\
3 & (6.3)\end{aligned}$ & 0.897 \\
\hline $\begin{array}{l}\text { Total days hospitalized } \\
\text { Mean } \pm \text { s.d. } \\
\text { Median (range) }\end{array}$ & $\begin{array}{r}70.5 \pm 59.0 \\
60.0(2-273)\end{array}$ & $\begin{array}{r}71.8 \pm 66.4 \\
46.0(2-273)\end{array}$ & $\begin{array}{r}69.4 \pm 52.9 \\
63.5(4-170)\end{array}$ & 0.984 & $\begin{array}{r}90.1 \pm 66.9 \\
104.0(2-273)\end{array}$ & $\begin{array}{c}58.6 \pm 50.8 \\
40.5(4-199)\end{array}$ & 0.046 \\
\hline $\begin{array}{l}\text { Days in ICU } \\
\text { Mean } \pm \text { s.d. } \\
\text { Median (range) }\end{array}$ & $\begin{array}{c}n=44 \\
10.6 \pm 17.3 \\
3.5(1-106)\end{array}$ & $\begin{array}{c}n=15 \\
9.4 \pm 11.8 \\
3.0(1-35)\end{array}$ & $\begin{array}{c}n=29 \\
11.2 \pm 19.8 \\
4.0(2-106)\end{array}$ & 0.772 & $\begin{array}{c}n=14 \\
15.7 \pm 27.4 \\
4.0(2-106)\end{array}$ & $\begin{array}{c}n=30 \\
8.2 \pm 9.6 \\
3.0(1-35)\end{array}$ & 0.182 \\
\hline $\begin{array}{l}\text { Place of discharge (\%) } \\
\text { Private residence } \\
\text { Hospital } \\
\text { Nursing home } \\
\text { Assisted living residence } \\
\text { Group living situation } \\
\text { Deceased }\end{array}$ & $\begin{array}{c}41(53.2) \\
24(31.2) \\
4(5.2) \\
5(6.5) \\
- \\
3(3.9)\end{array}$ & $\begin{array}{r}25(71.4) \\
5(14.3) \\
1(2.9) \\
2(5.7) \\
- \\
2(5.7)\end{array}$ & $\begin{array}{c}16(38.1) \\
19(45.2) \\
3(7.1) \\
3(7.1) \\
- \\
1(2.4)\end{array}$ & 0.010 & $\begin{array}{c}23(79.3) \\
2(6.9) \\
- \\
4(13.8) \\
- \\
-\end{array}$ & $\begin{array}{c}18(37.5) \\
22(45.8) \\
4(8.3) \\
1(2.1) \\
-\overline{-} \\
3(6.3)\end{array}$ & 0.000 \\
\hline $\begin{array}{l}\text { The ability to move at the time of discharge (\%) } \\
\text { Walking without equipments } \\
\text { Walking with a stick or crutches } \\
\text { Walking with a walker } \\
\text { Using a wheelchair } \\
\text { Using an electric wheelchair } \\
\text { Bed patient }\end{array}$ & $\begin{aligned} & (n=74) \\
22 & (29.7) \\
6 & (8.1) \\
5 & (6.8) \\
29 & (39.2) \\
7 & (9.5) \\
5 & (6.8)\end{aligned}$ & $\begin{aligned} & (n=33) \\
15 & (45.5) \\
3 & (9.1) \\
& - \\
12 & (36.4) \\
2 & (6.1) \\
1 & (3.0)\end{aligned}$ & $\begin{aligned} & (n=41) \\
7 & (17.1) \\
3 & (7.3) \\
5 & (12.2) \\
17 & (41.5) \\
5 & (12.2) \\
4 & (9.8)\end{aligned}$ & 0.046 & $\begin{array}{rl}(n=29) \\
10 & (34.5) \\
4 & (13.8) \\
1 & (3.4) \\
1 & 1(37.9) \\
2 & (6.9) \\
1 & (3.4)\end{array}$ & $\begin{aligned} & (n=45) \\
12 & (26.7) \\
2 & (4.4) \\
4 & (8.9) \\
18 & (40.0) \\
5 & (11.1) \\
4 & (8.9)\end{aligned}$ & 0.600 \\
\hline
\end{tabular}

Abbreviations: ASIA, American Spinal Injury Association; AIS, ASIA Impairment Scale; AIS A, motor-sensory complete; AIS B, motor complete-sensory incomplete; AIS C-D, motor-sensory incomplete; AIS E, normal examination; ICU, intensive care unit; TSCI, traumatic spinal cord injury UH, University Hospital.

Comparisons between patient groups according to the hospital district and age.

$P$-values $<0.05$ in bold and underlined.

age, $79.3 \%$ of the subjects were discharged home or to another private residence; in the age group $\geqslant 60$ years, $37.5 \%$ were discharged to a private residence and $45.8 \%$ to another hospital.

In addition, the patient groups exhibited statistically significant differences regarding alcohol consumption before the injury $(P=0.013)$. In the group of younger patients, $58.7 \%$ were injured under the influence of alcohol, whereas in the age group $\geqslant 60$ years, the figure was $27.1 \%$. The peak days for occurrence in the younger group of patients were Friday to Sunday, during which over $70 \%$ of the injuries took place (Figure 2).

\section{DISCUSSION}

The first year of centralized spinal cord care in Finland revealed a significantly higher incidence of TSCIs than expected, demonstrating 


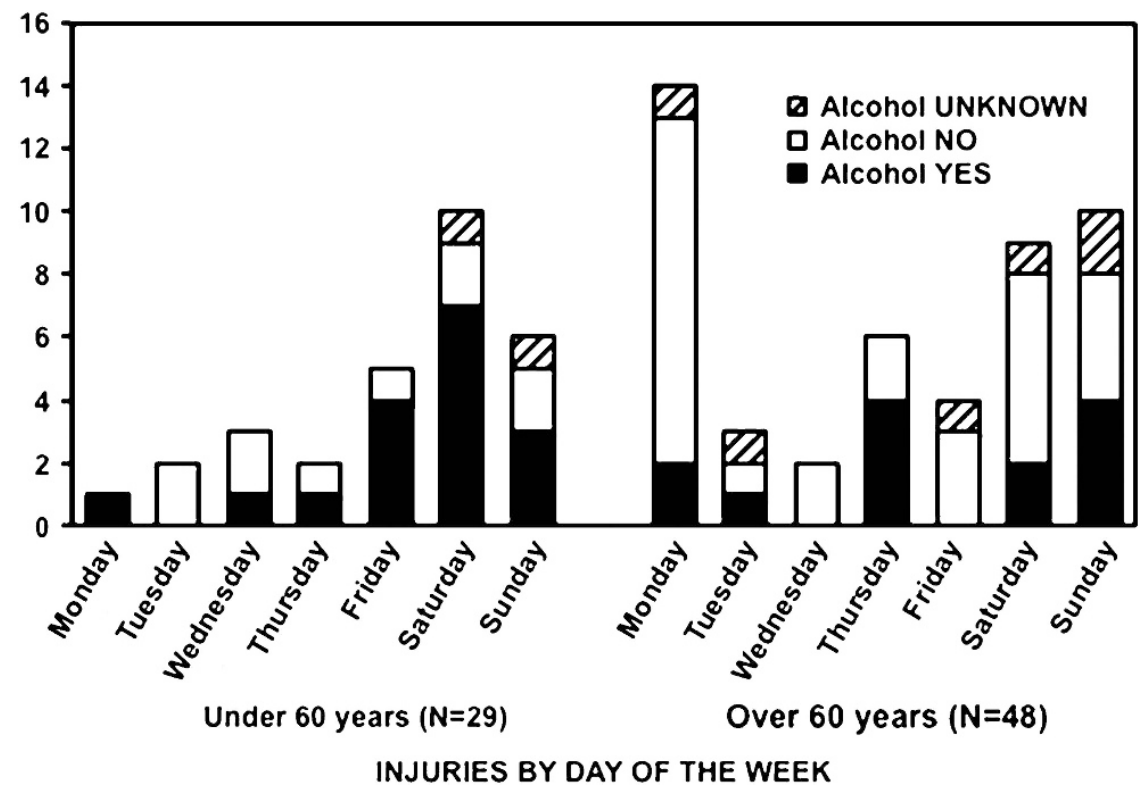

Figure 2 Consumption of alcohol before injury in relation to the number of injuries by day of the week in traumatic spinal cord injury (TSCI) patients younger and older than 60 years.

the previously hidden morbidity. The annual incidence of TSCI in the entire catchment area was 25.1 per million; in the UH districts with integrated trauma and SCI centers, the incidence exceeded this, being 38.1 per million. The incidences in the population over 16 years were 29.8 and 46.0, respectively, being two- to threefold greater than that reported in a previous study from Finland, in which the incidence in this age group was 13.8 per million. ${ }^{4}$

When observing all age groups, the numbers in the entire catchment area are comparable to those in recent retrospective incidence reports from Norway and Iceland, at 26.3 and 33.5 per million inhabitants, respectively. ${ }^{7,8}$ In addition, the incidence found in our study corresponds very well with the recently reported TSCI incidence estimate for Finland of 24.8 per million, which was based on a population-based regression model. ${ }^{12}$ The incidence of TSCI in the hospital districts with integrated trauma and SCI centers, at 38.1 per million inhabitants, approaches the average incidence of 40 per million reported in the United States ${ }^{13}$ and the recently published incidence estimate of 41 per million for Canada. ${ }^{14}$

The incidence in the hospital districts with SCI centers was twice as high as the incidence in the other hospital districts, at 19.6 cases per million, which referred patients to the study centers. There are some differences in the demographic characteristics of the populations, for example, the proportion of urban residents in the hospital districts. However, the most likely reasons behind the differences in the incidence are the incompleteness of centralized care and the more precise screening of acute trauma patients in SCI centers. These assumptions are supported by the slight, although not significant, difference in the ASIA Impairment Scale distribution and the lower proportion of independent walkers at discharge of the patients referred from other hospital districts. Most likely, the increasing awareness of spinal injuries among hospital staff and the systematic screening of new patients suspected of having SCI in established SCI centers has enhanced the identification of SCIs, particularly among patients with milder manifestations, revealing the hidden morbidity. Regardless of the decree of centralization, some patients from other hospitals may not have been referred to the SCI centers, for example, due to advanced age or minor motor disabilities. Differing procedures between SCI centers and other hospitals result in different distributions of injury severity indicators, such as ASIA Impairment Scale and walking ability, and are also reflected in the place of discharge. The same reasons are those that are most likely behind the difference between our results and the previous report of Käpylä Rehabilitation Centre. ${ }^{4}$ This hypothesis is also supported by our present finding of the increase in the mean age of occurrence from 42 years in a previous study ${ }^{4}$ to 58.7 years in our study.

Although the change in the mean age may in part reflect the differences in the selected study samples, the recent literature has also shown an increasing age at injury as well as an increasing proportion of cervical injuries and injuries due to falls. ${ }^{8,13,15,16}$ A similar tendency has been observed in Finland in recent decades. ${ }^{4,17}$ In our entire TSCI cohort, $64.9 \%$ of the patients were injured by falling and $70.1 \%$ were tetraplegic, supporting the trends reported in previous studies. Moreover, in the age group $\geqslant 60$ years in our study, over $80 \%$ of the patients were tetraplegic, and the number of upper cervical injuries (C1-C4) was almost threefold the number of lower cervical lesions. A similar tendency toward cervical injuries above C5 after the sixth decade has been detected previously. ${ }^{16,18}$

Interestingly, in our study, $85.4 \%$ of the patients 60 years of age or older were injured by falling, whereas patients under 60 years of age were primarily injured either in transportation accidents or by falling, which have traditionally been the main mechanisms of injury in the developed countries. ${ }^{19-21}$ The increasing age-adjusted incidence of fall-induced fracture-associated spinal injuries in elderly persons has been observed previously in Finland. ${ }^{17}$ Together with the aging of the population, this will challenge the health and support services, and older patients also have an increased frequency of complications and poorer prognosis. ${ }^{22}$ As an illustration of the challenge, the place of discharge differed between the age groups in our study despite equivalence in the completeness of injuries and in the ability to move at the time of discharge from the SCI center. Almost $80 \%$ of the patients aged younger than 60 years were discharged home directly after treatment in an SCI center, whereas $45.8 \%$ of the patients aged 60 years or older required a subsequent stay in another hospital before discharge home or to an assisted living residence. These findings 
emphasize the definitive need to target preventive measures against falls in elderly people.

In the younger patient groups, one of the key prevention areas should consider certain activities, such as driving and swimming, under the influence of alcohol. In our study, almost two-thirds of the patients younger than 60 years were injured under the influence of alcohol. When considering the entire sample, 39\% of the injuries were contributed by alcohol use. This is a similar proportion to that previously reported in Estonia, ${ }^{23}$ whereas a study from the USA has reported the presence of alcohol to be a contributing factor to injury in nearly $50 \%$ of cases tested. ${ }^{24}$ In addition, patients younger than 60 years of age were injured more often during weekends, most likely reflecting the prevailing binge drinking habits in Finland. ${ }^{25}$

The definitive strength of this study is the systematic clinical evaluation of all the new SCI patients according to the International SCI Core Data Set by specialist rehabilitation doctors working in SCI units. This practice both minimizes the risk of false-positive cases and leads to a low likelihood of missing cases, particularly in hospital districts with integrated trauma and SCI centers, as patients with milder injuries are also examined by specialists in the field. Although data from the Helsinki University Central Hospital were not available, the conduct of the study in two of the three SCI centers in Finland provides a good national coverage.

The major limitation of this study is the short 1-year study period. Therefore, a further follow-up to confirm the findings is necessary. Second, our data were based on the individuals admitted to the hospital and patients who died at the scene of the accident were not included, and this needs to be explored separately in the future. Thus, the incidence found in this study most likely represents the lower limit of the TSCI incidence.

Centralization of care resulted in a comprehensive SCI patient sample in the hospital districts with SCI centers, although centralization needs to be promoted in other hospital districts. The incidence rates of TSCI were surprisingly high, indicating the previously hidden morbidity. The epidemiological features of TSCI follow the trends of other developed countries, emphasizing the need to target prevention strategies toward fall prevention in the elderly and alcohol-related injuries in the younger population. The results need to be confirmed over an extended study period. The national SCI register is currently under development and will hopefully aid future follow-up of the epidemiology and development of patient care.

\section{DATA ARCHIVING}

There were no data to deposit.

\section{CONFLICT OF INTEREST}

The authors declare no conflict of interest.

\section{ACKNOWLEDGEMENTS}

The authors thank biostatistician Mika Helminen and the rehabilitation staff of the Tampere and Oulu University Hospitals for their assistance. This work was supported by funds from the Northern Ostrobothnia Hospital District, the
Medical Society Duodecim Oulu and the Pirkanmaa Regional Fund of the Finnish Cultural Foundation.

1 Parent S, Barchi S, LeBreton M, Casha S, Fehlings MG. The impact of specialized centers of care for spinal cord injury on length of stay, complications, and mortality: a systematic review of the literature. J Neurotrauma 2011; 28: 1363-1370.

2 Consortium for Spinal Cord Medicine. Early acute management in adults with spina cord injury: a clinical practice guideline for health-care professionals. J Spinal Cord Med 2008; 31: 403-479.

3 Ministry of Social Affairs and Health, Finland. Health Care Act 1326/2010: Centralization of Specialist Medical Care. Available at http://www.finlex.fi/fi/laki/ kaannokset/2010/en20101326.pdf (accessed on 12 May 2014).

4 Ahoniemi E, Alaranta H, Hokkinen EM, Valtonen K, Kautiainen H. Incidence of traumatic spinal cord injuries in Finland over a 30-year period. Spinal Cord 2008; 46: 781-784.

5 Biering-Sorensen E, Pedersen V, Clausen S. Epidemiology of spinal cord lesions in Denmark. Paraplegia 1990; 28: 105-118.

6 Divanoglou A, Levi R. Incidence of traumatic spinal cord injury in Thessaloniki, Greece and Stockholm, Sweden: a prospective population-based study. Spinal Cord, 2009; 47: 796-801.

7 Hagen EM, Eide GE, Rekand T, Gilhus NE, Gronning M. A 50-year follow-up of the incidence of traumatic spinal cord injuries in Western Norway. Spinal Cord 2010; 48 313-318

8 Knutsdottir S, Thorisdottir H, Sigvaldason K, Jonsson H Jr, Bjornsson A, Ingvarsson P. Epidemiology of traumatic spinal cord injuries in Iceland from 1975 to 2009. Spinal Cord 2012; 50: 123-126.

9 Waring WP 3rd, Biering-Sorensen F, Burns S, Donovan W, Graves D, Jha A et al. 2009 Review and Revisions of the International Standards for the Neurological Classification of Spinal Cord Injury. J Spinal Cord Med 2010; 33: 346-352.

10 DeVivo M, Biering-Sorensen F, Charlifue S, Noonan V, Post M, Stripling T et al. International spinal cord injury core data set. Spinal Cord 2006; 44: 535-540.

11 Official Statistics of Finland (OSF): Population structure. Helsinki, Finland: Statistics Finland. Available at http://www.tilastokeskus.fi/til/vaerak/index en.html, (accessed on 6 April 2014)

12 Fitzharris M, Cripps RA, Lee BB. Estimating the global incidence of traumatic spina cord injury. Spinal Cord 2014; 52: 117-122.

13 Devivo MJ. Epidemiology of traumatic spinal cord injury: trends and future implications. Spinal Cord 2012; 50: 365-372.

14 Noonan VK, Fingas M, Farry A, Baxter D, Singh A, Fehlings MG et al. Incidence and prevalence of spinal cord injury in Canada: a national perspective. Neuroepidemiology 2012; 38: 219-226.

15 O'Connor PJ. Forecasting of spinal cord injury annual case numbers in Australia. Arch Phys Med Rehabil 2005; 86: 48-51.

16 Pickett GE, Campos-Benitez M, Keller JL, Duggal N. Epidemiology of traumatic spinal cord injury in Canada. Spine (Phila Pa 1976) 2006; 31: 799-805.

17 Kannus P, Niemi S, Palvanen M, Parkkari J. Continuously increasing number and incidence of fall-induced, fracture-associated, spinal cord injuries in elderly persons. Arch Intern Med 2000; 160: 2145-2149.

18 Prasad VS, Schwartz A, Bhutani R, Sharkey PW, Schwartz ML. Characteristics of injuries to the cervical spine and spinal cord in polytrauma patient population: experience from a regional trauma unit. Spinal Cord 1999; 37: 560-568.

19 O'Connor RJ, Murray PC. Review of spinal cord injuries in Ireland. Spinal Cord 2006, 44: 445-448.

20 Chen Y, Tang Y, Vogel LC, Devivo MJ. Causes of spinal cord injury. Top Spinal Cord Inj Rehabil 2013; 19: 1-8.

21 Sabre L, Hagen EM, Rekand T, Asser T, Korv J. Traumatic spinal cord injury in two European countries: why the differences? Eur J Neurol 2013; 20: 293-299.

22 DeVivo MJ, Kartus PL, Rutt RD, Stover SL, Fine PR. The influence of age at time of spinal cord injury on rehabilitation outcome. Arch Neurol 1990; 47: 687-691.

23 Sabre L, Pedai G, Rekand T, Asser T, Linnamagi U, Korv J. High incidence of traumatic spinal cord injury in Estonia. Spinal Cord 2012; 50: 755-759.

24 Burke DA, Linden RD, Zhang YP, Maiste AC, Shields CB. Incidence rates and populations at risk for spinal cord injury: a regional study. Spinal Cord 2001; 39 274-278

25 Karlsson T, Kotovirta E, Tigerstedt C, Warpenius K. Alcohol in Finland. Consumption, harms and policy measures. Report 2013 013. National Institute for Health and Welfare, Helsinki. Available at http://urn fi/URN.ISBN:978-952-245-896-4 . (accessed on 6 April 2014) 